\title{
Asymmetric Synthesis of Propargylic $\alpha$-Chiral Tertiary Amines by Reductive Alkynylation of Tertiary Amides Using Ir/Cu Tandem Ca- talysis.
}

\author{
Toolika Agrawal, Kimberly D. Perez-Morales, Jermaine A. Cort, and Joshua D. Sieber*.
}

Department of Chemistry, Virginia Commonwealth University, 1001 West Main Street, Richmond, VA 23284-3208, USA.

Supporting Information Placeholder

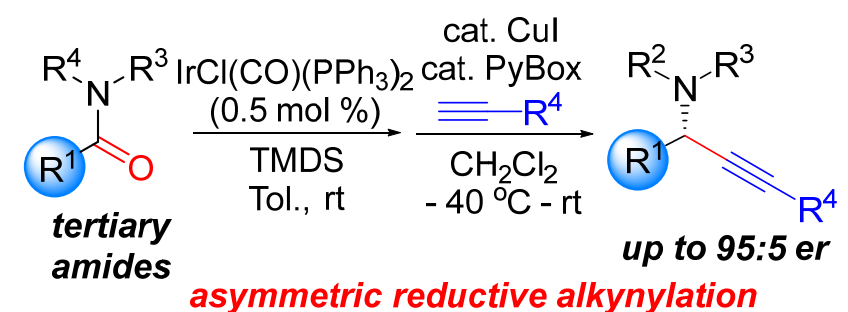

ABSTRACT: The development of an asymmetric protocol for the reductive alkynylation of amides to access important $\alpha$-chiral
tertiary propargylic amines is reported using tandem Ir-catalyzed hydrosilylation/enantioselective Cu-catalyzed alkynylation. The
reaction utilizes a $\mathrm{Cu} / \mathrm{PyB}$ ox catalyst system in the alkynylation step to achieve asymmetry and affords excellent yields with moderate
to good levels of enantiocontrol while employing low Ir-catalyst loadings $(0.5 \mathrm{~mol} \%)$.

$\alpha$-Chiral amines are prevalent motifs found in organic compounds and drug molecules leading to important biological activity. ${ }^{1}$ As a result, synthetic methods for the stereoselective preparation of $\alpha$-chiral amines is an important endeavor in organic chemistry. ${ }^{2}$ One powerful emerging strategy for the synthesis of $\alpha$-chiral amines utilizes amides as building blocks through partial reduction ${ }^{3}$ or activation $^{4,5}$ of the amide followed by reaction with nucleophiles (Figure 1A,B) in an overall deoxygenative process. ${ }^{6}$ The value of this approach arguably lies in the reliable access to amide building blocks 3 from ubiquitous carboxylic acid (1) and amine (2) precursors ${ }^{7}$ enabling a programmatic technique for the preparation of $\alpha$-chiral amines 4 . Such protocols are enabled by the conversion of amide $\mathbf{3}$ to an electrophilic $\mathrm{N}, \mathrm{O}$-aminal derivative $(\mathbf{5 , 6})$ that are subsequently functionalized with nucleophiles (Figure 1B).$^{3-6,8,9}$ Conversion of the amide into the requisite electrophilic species is achieved through either amide activation, ${ }^{4,5}$ typically employing $\mathrm{Tf}_{2} \mathrm{O}$, followed by trapping with an organometallic reagent to afford $\mathbf{5}$, or through partial reduction of the amide employing the Schwartz reagent $\left(\mathrm{Cp}_{2} \mathrm{ZrHCl}\right),{ }^{3 \mathrm{~g}} \mathrm{DIBAL},{ }^{3 \mathrm{~h}}$ or by $\mathrm{Ir}^{3 \mathrm{a}-\mathrm{f}}$ or Mocatalyzed $^{3 i, j}$ hydrosilylation giving 6 . Of these methods, reductive functionalization of tertiary amides through partial reduction by Ir-catalyzed hydrosilylation ${ }^{8}$ followed by nucleophile trapping have proven to be an attractive technique for the synthesis of $\alpha$-chiral tertiary amines due to the robustness of the Ircatalyzed hydrosilylation reaction that occurs at very low Ir-catalyst loading. ${ }^{6,8}$ However, the majority of these processes produce racemic $\alpha$-chiral amines, and enantioselective variants are extremely rare. ${ }^{9}$ As a result, our group became interested in developing catalytic asymmetric variants of these processes to
A Programmatic access to $\alpha$-chiral amines from amides

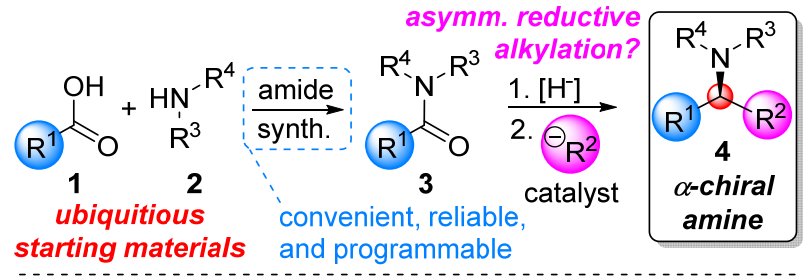

B Racemic access to $\alpha$-chiral amines by reductive alkylation ${ }^{3-6}$

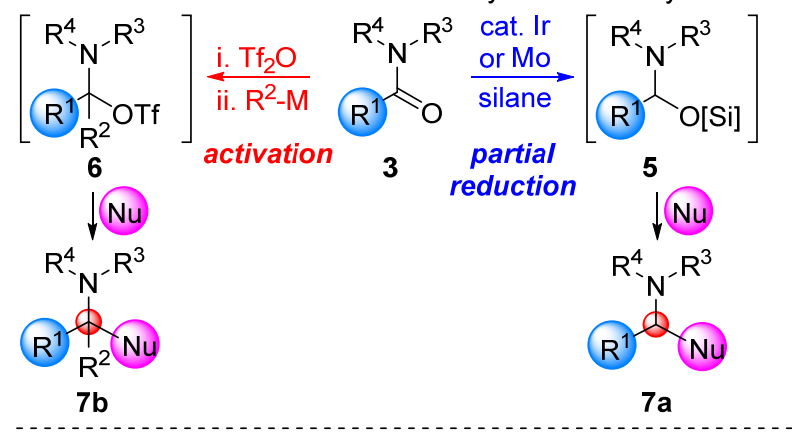

C This work: reductive asymmetric alkynylation

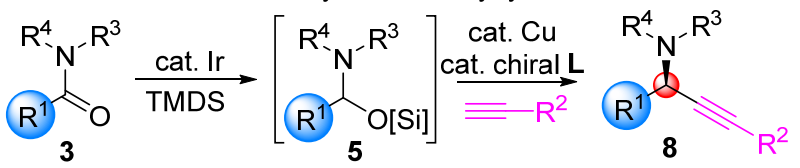

enantioselective $\alpha$-chiral tertiary propargylamine synthesis

Figure 1. Preparation of $\alpha$-Chiral Amines through Reductive Alkylation of Amides. 
access $\alpha$-chiral amines in enantioenriched form through coupling processes employing partially reduced amides from Ircatalyzed hydrosilylation as electrophiles. Furthermore, due to the reliable nature at which the amide functional group can be prepared synthetically, ${ }^{7}$ we reasoned such an asymmetric functionalization of amides would be a highly reliable technique to access $\alpha$-chiral tertiary amines. Based on the elegant work of Huang $^{3 \mathrm{c}}$ where racemic $\alpha$-chiral propargylic tertiary amines were prepared through tandem Ir-catalyzed amide hydrosilylation followed by $\mathrm{Cu}$-catalyzed alkynylation under ligandless conditions, we chose this reaction as an initial starting point to study by investigating the addition of chiral ligands to the reaction to determine if enantioselective ligand-accelerated catalysis $^{10}$ could be achieved to afford the $\alpha$-chiral propargylic tertiary amine products in high enantioselectivities (Figure 1C). During the course our investigations, Huang and Wang ${ }^{9 b}$ reported a $\mathrm{Cu} / \mathrm{bis}$ (phosphine) catalyzed version of this reaction providing products with high levels of enantiocontrol. This report prompted us to disclose our investigations into the analogous reaction where we have focused on application of chiral

Table 1. Chiral Ligand Survey ${ }^{a}$

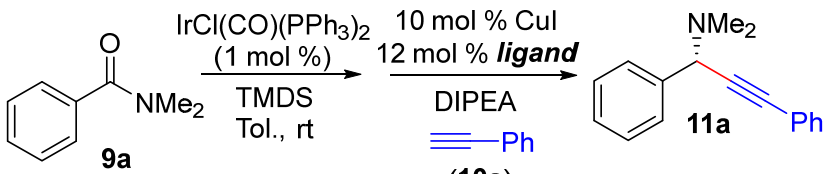

(10a)

\begin{tabular}{lllcc}
\hline entry & ligand & conditions & \% yield & er $^{\text {c }}$ \\
\hline 1 & none & d8-tol, rt, 6 h & 90 & $50: 50$ \\
2 & L1 & Tol, rt & 91 & $50: 50$ \\
3 & L2 & d8-Tol, rt, 1 h & 95 & $42: 58$ \\
4 & L3 & Tol, $-40^{\circ} \mathrm{C}$ to rt & 80 & $62: 38$ \\
5 & $\mathbf{L 4}$ & Tol, rt & 89 & $40: 60$ \\
6 & L4 & Tol, $-40^{\circ} \mathrm{C}$ to rt & 94 & $16: 84$ \\
7 & $\mathbf{L 5}$ & Tol, rt & 82 & $45: 55$ \\
8 & L6 & Tol, $-40^{\circ} \mathrm{C}$ to rt & 92 & $86: 14$ \\
9 & L6 & DCM, $-40^{\circ} \mathrm{C}$ to rt & 92 & $88: 12$ \\
$10^{d}$ & $\mathbf{L 6}$ & DCM, $-40^{\circ} \mathrm{C}$ to rt & 81 & $92: 8$ \\
$11^{d}$ & $\mathbf{L 7}$ & DCM, $-40^{\circ} \mathrm{C}$ to rt & 81 & $89: 13$
\end{tabular}

${ }^{a} \mathbf{9 a}(0.100 \mathrm{mmol}), \operatorname{IrCl}(\mathrm{CO})\left(\mathrm{PPh}_{3}\right)_{2}(1 \mathrm{~mol} \%), \operatorname{TMDS}(0.20$ $\mathrm{mmol})$ in $0.25 \mathrm{~mL}$ of toluene, $\mathrm{rt}, 1 \mathrm{~h}$; $\mathrm{CuI}(0.010 \mathrm{mmol})$, ligand $(0.012 \mathrm{mmol})$, DIPEA $(0.15 \mathrm{mmol}), \mathbf{1 0 a}(0.15 \mathrm{mmol})$ in $0.50 \mathrm{~mL}$ of solvent. See the Supporting Information for further details. ${ }^{b}$ Isolated yield. ${ }^{c}$ Value determined by chiral HPLC analysis. ${ }^{d}$ Reaction performed in the absence of DIPEA using $5 \mathrm{~mol} \% \mathrm{CuI}$ and $7 \mathrm{~mol} \%$ ligand.

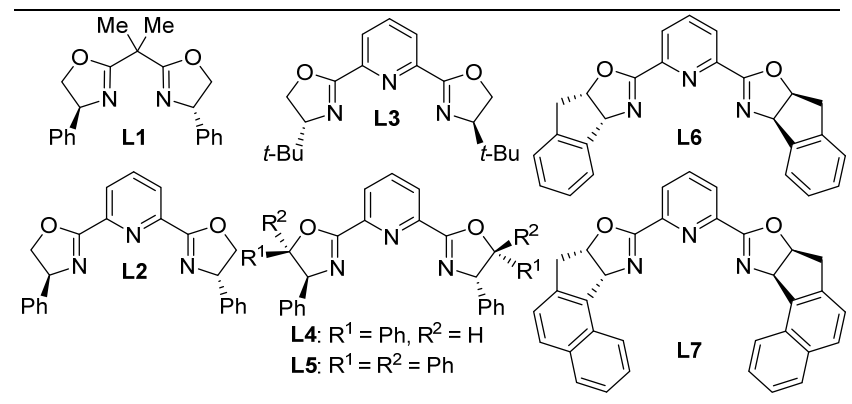

PyBox ligands to achieve enantiocontrol. Herein we report our findings on the development of an enantioselective $\alpha$-chiral propargylic amine synthesis through tandem partial amide reduction by Ir-catalyzed hydrosilylation followed by asymmetric $\mathrm{Cu} /$ PyBox catalyzed alkynylation.

Initial investigation into the feasibility of an asymmetric tandem reductive amide alkynylation reaction was carried out utilized $N, N$-dimethylbenzamide (9a) in an Ir-catalyzed hydrosilylation reaction followed immediately by $\mathrm{Cu}$-catalyzed coupling with phenylacetylene (10a) to afford $\alpha$-chiral propargylic amine 11a (Table 1). Use of chiral Ph-Box ligand L1 discouragingly afforded product $\mathbf{1 1 a}$ as a racemate (entry 2). As a result, a series of PyBox ligands (L2 - L7) were next investigated under the hypothesis that the added chelation available with these ligands may enable a more selective catalyst (entries 3 11). Indeed, use of PyBox $\mathbf{L} 2$ afforded non-racemic 11a, albeit with poor enantioselectivity, and ligand accelerated catalysis was observed relative to the reaction in the absence of ligand by monitoring reaction progress throughout the alkynylation step using ${ }^{1} \mathrm{HNMR}$ spectroscopic analysis while performing the reactions in $\mathrm{d} 8$-toluene (entry 3 vs 1). The reaction employing ligand $\mathbf{L} 2$ (entry 3) was complete in $1 \mathrm{~h}$ whereas the ligandless reaction (entry 1) required $>4 \mathrm{~h}$ to reach completion. Increasing the steric size of the substituents at the stereogenic centers of the PyBox ligand (i.e. L3), and reducing the reaction temperature, did not afford significant improvements in enantioinduction (entry 4). However, it was found that substitution on the $C$ atom of the $\mathrm{C}-\mathrm{O}$ group of the oxazoline ring of the PyBox ligand (i.e. $\mathbf{L 4}$ - L7 vs $\mathbf{L} 2$ - L3) allowed for significant improvements in enantiocontrol (entries 3 and 4 vs entries $5-11$ ). ${ }^{11}$ Performing the reaction at $-40{ }^{\circ} \mathrm{C}$ was found to be optimal ${ }^{12}$ and led to improved stereocontrol relative to reactions performed at rt (entry 5 vs 6). Ultimately, aminoindanol-derived PyBox ligand $\mathbf{L 6}$ afforded the highest levels of enantiocontrol (entries 8 - 10). Dichloromethane (entry 9,10) was identified as the optimal reaction solvent, ${ }^{12}$ which may be due to the fact that L6 was found to have poor solubility in most organic solvents except for $\mathrm{CH}_{2} \mathrm{Cl}_{2}$. Additionally, no exogenous amine base was needed in the alkynylation reaction and the $\mathrm{Cu}$-catalyst loading could be reduced to $5 \mathrm{~mol} \%$ with a slight reduction in yield, but with improved stereoselectivity (entry 10). Finally, extending the $\pi$ system of the PyBox ligand as in $\mathbf{L} 7$ did not lead to any further improvements.

After having identified optimal conditions for the tandem reductive amide alkynylation reaction (Table 1, entry 10), the substrate scope of this process was next investigated (Scheme 1). Varying the $\mathrm{R}^{1}$-substituent of amide 9 employing phenylacetylene (10a) generally afforded similar results (11a-h). A small electronic effect may be observed where electron-rich aromatic $\mathrm{R}^{1}$-groups afforded slightly higher levels of enantiocontrol relative to electron-poor aromatics (11b,d vs 11e-h). Reduction in the steric size of the $\mathrm{R}^{1}$-group led to a decrease in enantioselectivity (11i). Varying the $\mathrm{R}^{4}$-group of the alkyne nucleophile (10) showed a dramatic effect on enantioselectivity $(\mathbf{1 1} \mathbf{j}-\mathbf{x})$. Alkynes bearing aromatic $\mathrm{R}^{4}$-groups (10j-q) generally gave similar levels of enantiocontrol, and amides bearing aliphatic $\mathrm{R}^{1}$-groups could also be used $(\mathbf{1 1 1}, \mathbf{q})$. However, when the $\mathrm{R}^{4}$-group of the alkyne was a smaller aromatic ring (10r), an ester moiety (10s), or an aliphatic group $(\mathbf{1 0 w}, \mathbf{x})$ very low levels of enantioinduction were obtained. Interestingly, when using a conjugated aromatic group on the alkyne $(\mathbf{1 0 t})$ or amide groups $(\mathbf{1 0 u}, \mathbf{v})$, similar levels of enantiocontrol to that obtained with aromatic 
Scheme 1. Scope of the Tandem Reductive Amide Asymmetric Alkynylation Reaction ${ }^{a}$
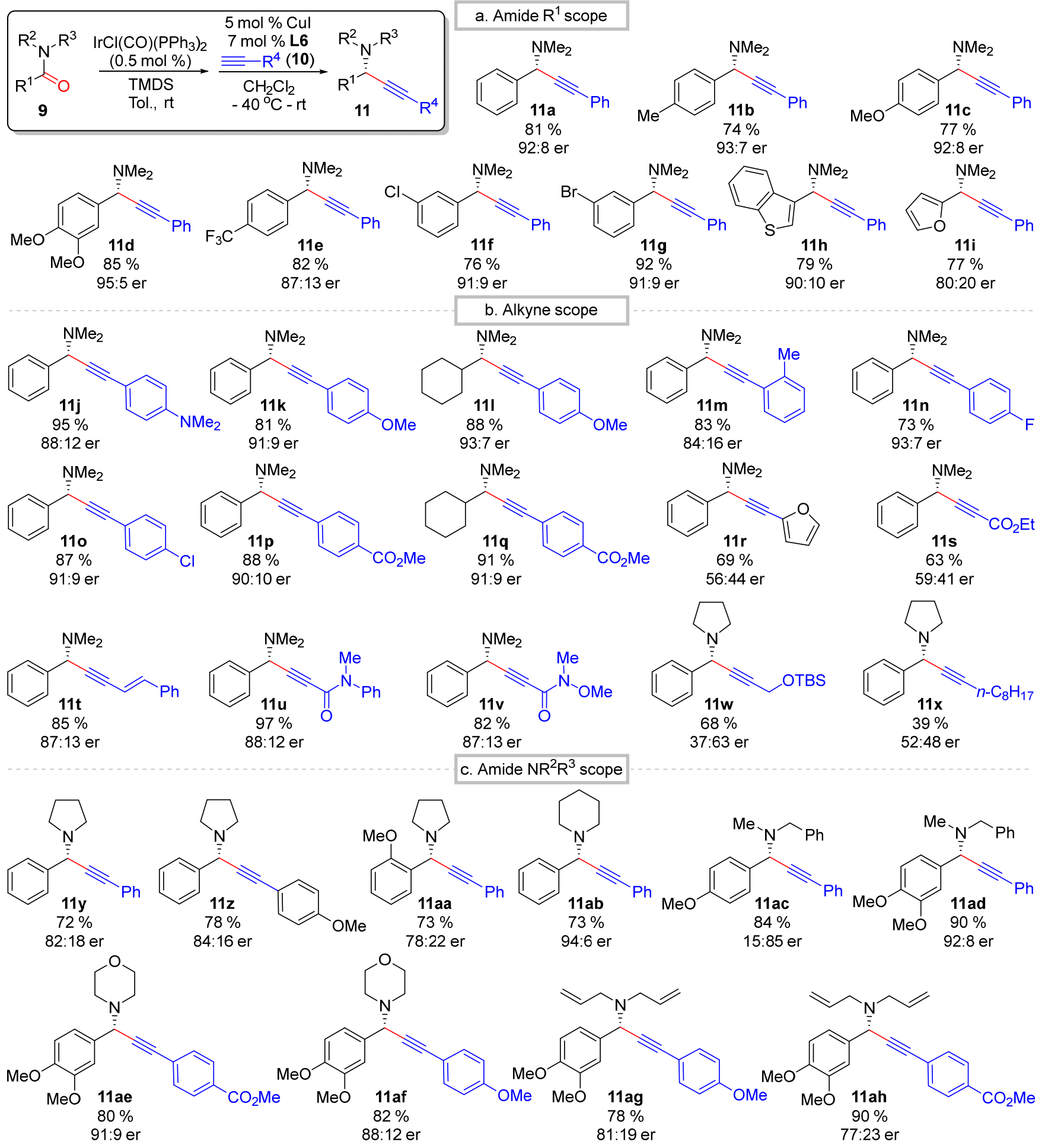

${ }^{a}$ Reaction utilizes $0.400 \mathrm{mmol}$ of amide 9; see the Supporting Information.

alkynes was restored. Finally, analysis of the $\mathrm{NR}^{2} \mathrm{R}^{3}$ group of amide 9 demonstrated that cyclic (11y-ab, 11ae, 11af) and acyclic (11ac, 11ad, 11ag, 11ah) amino-groups were tolerated with similar levels of enantiocontrol. Six-membered carbocyclic amines (11ab) afforded improved stereoselectivity relative to smaller five-membered versions (11y). Acyclic amino-groups larger than $\mathrm{CH}_{3}$ generally afforded reduced levels of enantiocontrol (11ac, 11ad, 11ag, 11ah).
The tandem Ir-catalyzed amide reduction/enantioselective $\mathrm{Cu}$-catalyzed alkynylation reaction could easily be performed on a $1.0 \mathrm{mmol}$ scale with reduction in the $\mathrm{Cu}$ catalyst loading to 2 mol \% providing near quantitative yield of 11a in 92.7:7.3 er (Scheme 2a). Furthermore, the synthetic utility of chiral propargylic amines in organic synthesis has already been extensively demonstrated. ${ }^{13}$ For example, conversion of $\mathbf{1 1 y}$ to axially chiral internal allene $\mathbf{1 3}$ with complete chirality transfer (CT) has already been reported using $\mathrm{AgNO}_{3}$ (Scheme 2b). ${ }^{14}$ 
Additionally, 11ab was previously shown ${ }^{9 b}$ to be converted into cis-alkene 12 or stereodefined vinyl iodide 14 with complete conservation of enantiomeric excess (cee) in both cases.

Scheme 2. Practicality of the Amide Reductive Alkynylation Method.

a) $1.0 \mathrm{mmol}$ scale reaction:

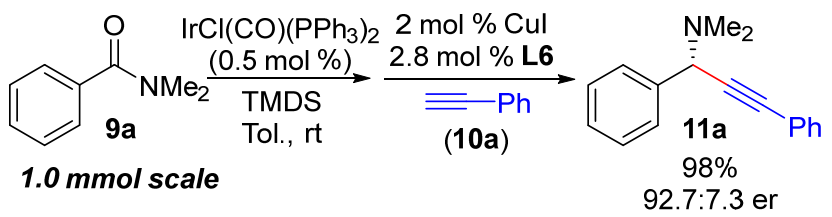

b) Synthetic utility:

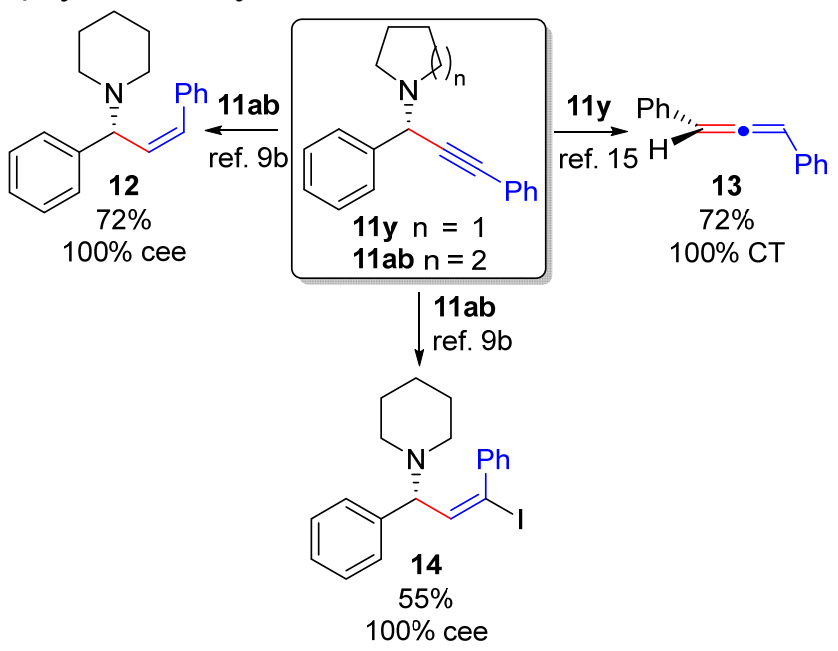

In conclusion, an asymmetric reductive alkynylation of amides using tandem $\mathrm{Ir}$ - and $\mathrm{Cu}$-catalysis for the synthesis of $\alpha$ chiral tertiary propargylic amines was described. Moderate to good enantioselectivities were observed using an aminoindanol-derived PyBox ligand when employing alkynamides or aromatic-substituted alkynes as the coupling partner in the alkynylation step.

\section{ASSOCIATED CONTENT}

\section{Supporting Information}

The Supporting Information is available free of charge on the ACS Publications website.

Detailed experimental procedures, compound characterization data, chiral HPLC traces, and copies of NMR spectra (PDF)

\section{AUTHOR INFORMATION}

\section{Corresponding Author}

* Joshua D. Sieber - ${ }^{a}$ Department of Chemistry, Virginia Commonwealth University, 1001 West Main Street, Richmond, VA 23284-3028, USA. ${ }^{b}$ Medicines for All Institute, VCU, Biotech 8, $737 N 5^{\text {th }}$ Street, Richmond, VA 23219, USA. ORCID: 00000001-6607-5097; Email: jdsieber@vcu.edu

\section{Notes}

The authors declare no competing financial interest.

\section{ACKNOWLEDGMENT}

Startup funding from the Virginia Commonwealth University is gratefully acknowleged. K.D.P-M. acknowledges the NSF for a summer REU fellowship (CHE-1851916). We thank Dr. Joseph Turner (VCU) for assistance in collecting HRMS data.

\section{REFERENCES}

(1) (a) Hall, A.; Provins, L.; Valade, A. Novel Strategies to Activeate the Dopamine $\mathrm{D}_{1}$ Receptor: Recent Advances in Orthosteric Agonism and Positive Allosteric Modulation. J. Med. Chem. 2019, 62, 128 - 140. (b) Perez, M.; Ayad, T.; Maillos, P.; Poughon, V.; Fahy, J.; Ratovelomanana-Vidal, V. Synthesis and Antiproliferative and Metabolic Evalustions of Novel Securinine Derivatives. ACS Med. Chem. Lett. 2016, 7, 403 - 407. (c) Reddy, G. O.; Sarma, M. R.; Chandrasekhar, B.; Babu, J. M.; Prasad, A. S. R.; Raju, C. M. H. A Study and Identification of Potential By-Products of Sibutramine. Org. Process Research \& Development 1999, 3, 488 - 492. (d) Tamura, K.; Kumagai, N.; Shibasaki, M. An Enantioselective Synthesis of the Key Intermediate for Triazole Antifungal Agents; Application to the Catalytic Asymmetric Synthesis of Efinaconazole (Jublia). J. Org. Chem. 2014, 79, $3272-$ 3278. (e) Bolognesi, M. L.; Bartolini, M.; Cavalli, A.; Andrisano, V.; Rosini, M.; Minarini, A.; Melchiorre, C. Design, Synthesis, and Biological Evaluation of Conformationally Restricted Rivastigmine Analogues. J. Med. Chem. 2004, 47, 5945 - 5952.

(2) (a) Trowbridge, A.; Walton, S. M.; Gaunt, M. J. New Strategies for the Transition-Metal Catalyzed Synthesis of Aliphatic Amines. Chem. Rev. 2020, 120 (5), 2613-2692. (b) Nugent, T. C.; El-Shazly, M. Chiral Amine Synthesis - Recent Developments and Trendsfor Enamide Reduction, Reductive Amination, and Imine Reduction. Adv. Synth. Catal. 2010, 352 (5), 753-819. (c) Li, W., Zhang, X., Eds. Stereoselective Formation of Amines; Topics in Current Chemistry; Springer-Verlag: Berlin, 2014. (d) Wang, C.; Xiao, J. Asymmetric Reductive Amination. In Top. Curr. Chem. Li, W., Zhang, X., Eds.; Springer-Verlag: Berlin, 2014, 343, 261-282. (e) Xie, J. H.; Zhu, S. F.; Zhou, Q. L. Transition Metal-Catalyzed Enantioselective Hydrogenation of Enamines and Imines. Chem. Rev. 2011, 111 (3), 1713-1760. (f) Kobayashi, S.; Ishitani, H. Catalytic Enantioselective Addition to Imines. Chem. Rev. 1999, 99 (5), 1069-1094.

(3) Selected examples: (a) Ong, D. Y.; Fan, D.; Dixon, D J.; Chiba, S. Transition-Metal-Free Reductive Functionalization of Tertiray Carboxamides and Lactams for $\alpha$-Branched Amine Synthesis. Angew. Chem. Int. Ed. 2020, 59, 11903 - 11907. (b) Xie, L. G.; Dixon, D. J. Tertiary Amine Synthesis: Via Reductive Coupling of Amides with Grignard Reagents. Chem. Sci. 2017, 8 (11), 7492-7497. (c) Huang, P. -Q.; Ou, W.; Han, F. Chemoselective Reductive Alkynylation of Tertiary Amides by $\mathrm{Ir}$ and $\mathrm{Cu}(\mathrm{I})$ Bis-Metal Sequential Catalysis. Chem. Commun. 2016, 52, 11967 - 11970. (d) Ou, W.; Han, F.; Hu, X. -N.; Chen, H.; Huang, P. -Q. Iridium-Catalyzed Reductive Alkylations of Secondary Amides. Angew. Chem. Int. Ed. 2018, 57, $11354-11358$. (e) Xie, L. -G.; Dixon, D. J. Iridium-Catalyzed Reductive Ugi-Type Reactions of Tertiary Amides. Nat. Commun. 2018, 9, 2841 - 2848. (f) Fuentes de Arriba, A. L.; Lenci, E.; Sonawane, M.; Formery, O.; Dixon, D. J. Iridium-Catalyzed Reductive Strecker Reaction for LateStage Amide and Lactam Cyanation. Angew. Chem. Int. Ed. 2017, 56, 3655 - 3659. (g) Schwartz: Oda, Y.; Sato, T.; Chida, N. Direct Chemoselective Allylation of Inert Amide Carbonyls. Org. Lett. 2012, 14, 950 - 953. (h) DIBAL: Shirokane, K.; Kurosaki, Y.; Sato, T.; Chida, N. A Direct Entry to Substituted $N$-Methoxyamines from $N$ Methoxyamides via $N$-Oxyiminium Ions. Angew. Chem. Int. Ed. 2010, 49, 6369 - 6372. Mo: (i) Trillo, P.; Slagbrand, T.; Adolfsson, G. Straightforward $\alpha$-Amino Nitrile Synthesis Through $\mathrm{Mo}(\mathrm{CO})_{6-}$ Catalyzed Reductive Functionalization of Carboxamides. Angew. Chem. Int. Ed. 2018, 57, 12347 - 12351. (j) Slagbrand, T.; Kervefors, G.; Tinnis, F.; Adolfsson, H. An Efficient One-pot Procedure for the Direct Preparation of 4,5-Dihydroisoxazoles from Amides. Adv. Synth. Catal. 2017, 359, $1990-1995$.

(4) (a) Xiao, K. -J.; Luo, J. -M.; Ye, K. -Y.; Wang, Y.; Huang, P. Q. Direct, One-pot Sequential Reductive Alkylation of Lactams/Amides with Grignard and Organolithium Reagents through Lactam/Amide Activation. Angew. Chem. Int. Ed. 2010, 49, 3037 - 3040. (b) Xiao, K. -J.; Wang, A. -E.; Huang, P. -Q. Direct Transformation of Secondary Amides into Secondary Amines: Triflic Anhydride Activated Reductive Alkylation. Angew. Chem. Int. Ed. 2012, 51, 8314 - 8317. 
(5) Reviews: (a) Kaiser, D.; Bauer, A.; Lemmerer, M.; Maulide, N. Amide Activation: an Emerging Tool for Chemoselective Synthesis. Chem. Soc. Rev. 2018, 47, 7899 - 7925. (b) Kaiser, D.; Maulide, D. Makign the Least Reactive Electrophile the First in Class: Domino Electrophilic Activation of Amides. J. Org. Chem. 2016, 81, $4421-$ 4428.

(6) Reviews: (a) Matheau-Raven, D.; Gabriel, P.; Leitch, J. A.; Almehmadi, Y. A.; Yamazaki, K.; Dixon, D. J. Catalytic Reductive Functionalization of Tertiary Amides Using Vaska's Complex: Synthesis of Complex Tertiary Amine Building Blocks and Natural Products. ACS Catal.2020, 10 (15), 8880-8897. (b) Ong, D. Y.; Chen, J. -H.; Chiba, S. Reductive Functionalization of Carboxamides: A Recent Update. Bull. Chem. Soc. Jpn. 2020, 93, 1339 - 1349. (c) Tahara, A.; Nagashima, H. Recent Topics of Iridium-Catalyzed Hydrosilylation of Tertiary Amides to Silylhemiaminals. Tetrahedron Lett. 2020, 61, 151423. (d) Volkov, A.; Tinnis, F.; Slagbrand, T.; Trillo, P.; Adolfsson, H. Chemoselective Reduction of Carboxamides. Chem. Soc. Rev. 2016, $45,6685-6697$

(7) (a) Dunetz, J. R.; Magano, J.; Weisenburger, G. A. Large-Scale Applications of Amide Coupling Reagents for the Synthesis of Pharmaceuticals. Org. Process Res. Dev. 2016, 20(2), 140-177. (b) Pattabiraman, V. R.; Bode, J. W. Rethinking Amide Bond Synthesis. Nature 2011, 480, 471 - 479. (c) Brown, D. G.; Bostrom, J. Analysis of Past and Present Synthetic Methodologies on Medicinal Chemistry: Where have all the New Reactions Gone? J. Med. Chem. 2016, 59, 4443 4458. (d) Seavill, P. W.; Wilden, J. D. The Preparation and Applications of Amides Using Electrosynthesis. Green Chem. 2020, 22, 7737 -7759 .

(8) Motoyama, Y.; Aoki, M.; Takaoka, N.; Aoto, R.; Nagashima, H. Highly Efficient Synthesis of Aldenamines from Carboxamides by Iridium-Catalyzed Silane-Reduction/Dehydration under Mild Conditions. Chem. Commun. 2009, 1574-1576.

(9) (a) Chen, D. -H.; Sun, W. -T.; Zhu, C. -J.; Lu, G. -S.; Wu, D. P.; Wang, A. -E.; Huang, P. Q. Enantioselective Reductive Cyanation and Phosphonylation of Secondary Amides by Iridium and Chiral Thiourea Sequential Catalysis. Angew. Chem. Int. Ed. 2021, 60, 8827 8831. (b) Li, Z.; Zhao, F.; Ou, W.; Huang, P. -Q.; Wang, X. Asymmetric Deoxygenative Alkynylation of Tertiary Amides Enabled by
Iridium/Copper Bimetallic Relay Catalysis. Angew. Chem. Int. Ed. 2021, doi.org/10.1002/anie.202111029.

(10) Berrisford, D. J.; Bolm, C.; Sharpless, K. B. Ligand accelerated catalysis. Angew. Chem. Int. Ed. 1995, 34, 1059-1070.

(11) For a similar observation in Cu-catalyzed asymmetric alkynylation of cyclic $\mathrm{N}, \mathrm{O}$-aminals, see: Guan, W.; Santana, S. O.; Liao, J.; Henninger, K.; Watson, M. P. Enantioselective Alkynylation of Unstabilized Cyclic Iminium Ions. ACS Catal. 2020, 10, 13820 - 13824.

(12) See the Supporting Information for additional data.

(13) (a) Gommermann, N.; Knochel, P. Practical Highly Enantioselective Synthesis of Terminal Propargylamines. An Expeditious Synthesis of (S)-(+)-Coniine. Chem. Commun. 2004, 2324 - 2325. (b) Koradin, C.; Knochel, P. Enantioselective Synthesis of Prpargylamines by Copper-Catalyzed Addition of Alkynes to Enamines. Angew. Chem. Int. Ed. 2002, 41, 2535 - 2538. (c) Liu, Q.; Xu, H.; Li, Y.; Yao, Y.; Zhang, X.; Guo, Y.; Ma, S. Pyrinap Ligands for Enantioselective Synthesis of Amines. Nat. Commun. 2021, 12, https://doi.org/10.1038/s41467-020-20205-0.

(14) Zhao, C.; Seidel, D. Enantioselective $A^{3}$ Reactions of Secondary Amines with a $\mathrm{Cu}(\mathrm{I}) /$ Acid-Thiourea Catalyst Combination. J. Am. Chem. Soc. 2015, 137, $4650-4653$. 